Sensors 2003, 3, 504-508

sensors

ISSN 1424-8220

(C) 2003 by MDPI

http://www.mdpi.net/sensors

\title{
Semiconductor Sensors Application for Definition of Factor of Ozone Heterogeneous Destruction on Teflon Surface
}

\author{
Ludmila A. Obvintseva, Fatima Kh. Chibirova*, Serge A. Kazakov, Alexander K. Avetisov, \\ Marina V. Strobkova and Nataliya V. Finogenova
}

Karpov Research Institute For Physical Chemistry, Russia 105064, Moscow, ul. Vorontsovo Pole, 10. Tel. (095) 735-65-57, Fax. (095) 437-28-10,

* Author to whom correspondence should be addressed : chibir@cc.nifhi.ac.ru

Received: 1 May 2003 / Accepted: 5 October 2003 / Published: 5 December 2003

\begin{abstract}
In our paper we present the results of our research, which was carried out by means of semiconductor sensor techniques (SCS), which allowed evaluating heterogeneous death-rate of ozone $(\gamma)$ Teflon surface. When ozone concentration is near to Ambient Air Standard value, $\gamma$ is assessed to be equal to $6,57 * 10^{-7}$. High technique response provide possibility to determine ozone contents in the air media and the percentage of ozone, decomposed on the communication surfaces and on the surfaces of installation in the low concentration range (1-100 ppb).
\end{abstract}

Keywords: semiconductor sensors, heterogeneous death-rate of ozone, Teflon

\section{Introduction}

Both environmental problems, connected to ozone, and its wide implementation in chemical technological processes cause significant interest to ozone behaviour under various conditions [1]. As a consequence, the demand arises for measurements techniques of low ozone concentrations (1-100 ppb) in the ambient air. This concentration range includes the variations of ozone concentrations during a day, and also Ambient Air Standard for ozone (AAS), (50 ppb). Only high precision techniques provide measurements of such concentration ranges, but the risk exists of the distortion of the measured concentration values caused by ozone decomposition on the walls of the installations or 
connections. Ozone easily decomposes even on the inert surfaces, which results in a significant drop of ozone concentration during the test. Ozone losses on the communication surfaces can be estimated $\gamma$, heterogeneous death-rate of ozone, which equals to the ration between the number of decomposed molecules to the total number collisions of molecules with the surface. For the purpose of evaluation of heterogeneous death-rate of gas molecules on the solid surfaces, the method of tubes is often used. The tubes are supplied with various kinds of sensors to register the changes of gas mixture composition at the tube inlet and outlet. Low sensor sensitivity under the conditions of low molecules concentration results in some problems with $\gamma$ evaluation. In such cases the researchers often have to extrapolate the $\gamma$ values, which were determined at high gas concentrations, to the low concentration region, which is rather difficult to realise with sufficient correctness as the concentration dependence of $\gamma$ value is rather complicated [1].

In our work we use semiconductor sensor (SCS) as ozone sensor for $\gamma$ evaluation by means of tubes techniques [2,3]. High SCS sensitivity allows for measurements at low ozone concentrations. Heterogeneous death-rate of ozone $(\gamma)$ is evaluated on the surface of Teflon tubes at ozone concentration in the air in the vicinity of AAS level, i.e. $50 \mathrm{ppb}$. Teflon holds an important position among the construction materials, which are implemented in the atmosphere monitoring systems, ozone generators and analysers, and also in the installations for metrological validation of the above systems and device. Nevertheless, there are only a few references on $\gamma$ values on Teflon $[1,4]$, and they are determined at high ( $4 \%)$ ozone concentrations in the air.

\section{Experimental procedure}

Heterogeneous death-rate $\gamma$ was evaluated by tube method, semiconductor sensor being used as ozone detector. Sensitive layer $\left[\operatorname{In}_{2} \mathrm{O}_{3}\left(\alpha-\mathrm{Fe}_{2} \mathrm{O}_{3} 3 \%\right)\right]$ was applied onto the insulating substrate with the surface area of $3 \times 3 \mathrm{~mm}^{2}$. Sensor construction and production procedure are presented in papers [2,3]. Electroconductivity of sensitive layer is an electrophysical characteristic of a sensor, which is proportionate to ozone concentration. Sensor electroconductivity signal was detected as analogous one with $1 \mathrm{~Hz}$ frequency by means of special electronic unit, which was specially developed for this purpose, and was transferred to PC through Lcard 134 interface. UV generator with variable output was used as ozone source; it was calibrated by means of standard DASIBI-1008 spectrophotometer. Sensor was placed in the air flow $\left(400 \mathrm{~cm}^{3} / \mathrm{min}\right)$, produced by self-regulating ejector. Ozone-air mixture extraction was carried out by means of Teflon tubes (Ф-4Д-Э brand, 0,2 cm diameter) out of ozone flow, produced by generator $\left(2000 \mathrm{~cm}^{3} / \mathrm{min}\right)$, to the sensor. Tube length was modified during the tests: $1 \mathrm{~cm}, 500 \mathrm{~m}$ and $1000 \mathrm{~cm}$. The sensor was calibrated with the help of a tube with minimal length of $1 \mathrm{~cm}$. Ozone concentration was fixed by selecting of necessary generator capacity. Calibration curve, i.e. ozone concentration (ppb) dependence of stationary signal value of the sensor (U, B) is presented in Fig. 1 ozone concentration range from 30 to 85 ppb. Extrapolation is done to the range of lower concentrations. 


\section{Results and Discussion}

The kinetic curves of sensor signal are presented in Fig. 2 for predetermined ozone concentration of $50 \mathrm{ppb}$ in the flow, which were obtained with the use of tubes of the length of $1 \mathrm{~cm}$ (upper curve), of $500 \mathrm{~cm}$ (middle curve) and of $1000 \mathrm{~cm}$ (bottom curve). The points of generator turn on and off are marked by arrows. As you can see, increase of tube length results in substantial decrease of stationary sensor signal level. Let us consider ozone losses on the surface of the tube of $1 \mathrm{~cm}$ to be negligible and the sensor signal level to be equal to ozone concentration of $50 \mathrm{ppb}$, (upper curve, Fig. 2).

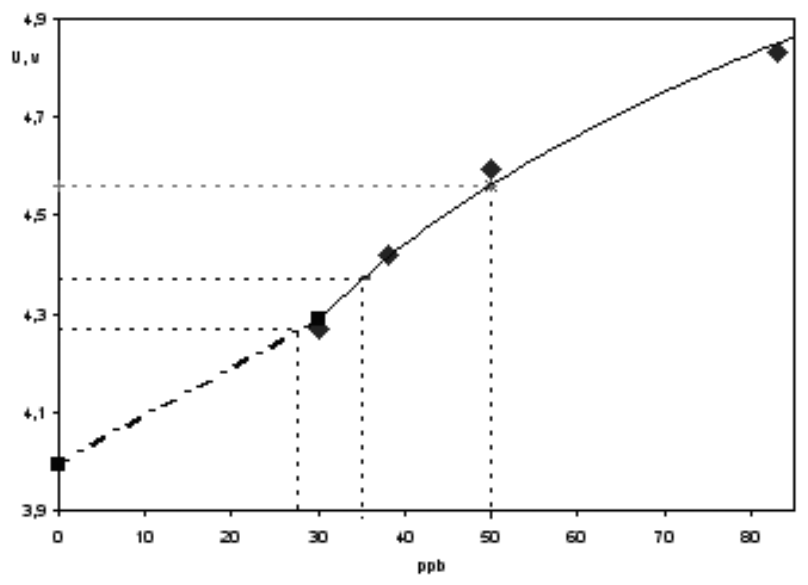

Figure. 1 Ozone concentration dependence of sensor signal (Calibration curve).

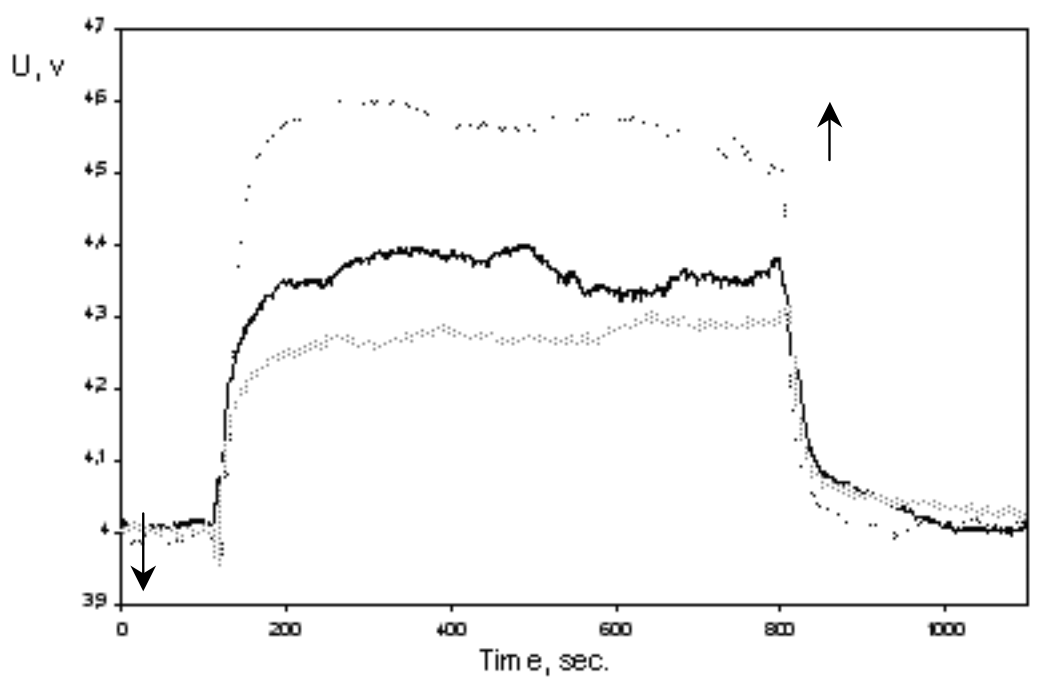

Figure. 2 Sensor response for $50 \mathrm{ppb}$ of ozone in the air, when Teflon tubes of various lengths are used: $1 \mathrm{~cm}$ (upper curve), $500 \mathrm{~cm}$ (middle curve), $1000 \mathrm{~cm}$ (bottom curve). $\downarrow$ - ozone generator ON, $\uparrow$ - ozone generator OFF. 
With the help of sensor calibration curve (Fig. 1) we can determine conformity between ozone concentration and sensor signals stationary levels at outlets of tubes of $500 \mathrm{~cm}$ and $1000 \mathrm{~cm}$. The indicated values comprise, accordingly, 37 and 27,5 ppb. Hence, ozone losses, which we observe in the flow, are rather substantial and equal to 26 and $46 \%$, i.e. have the same order of magnitude as measured ozone concentration.

The heterogeneous death-rate of ozone on Teflon surface can be determined on the basis of the obtained data. Computation was carried out according to the formula, presented in the paper [1]:

$$
\gamma=\frac{4 \omega}{S V_{t}} \ln \frac{\left[O_{3}\right]_{0}}{\left[O_{3}\right]}
$$

where: $\gamma$ is heterogeneous death-rate of ozone; $\omega$ - flow rate, equalled to $6,7 \mathrm{~cm}^{3} / \mathrm{sec}, \mathrm{V}_{\mathrm{t}^{-}}$heat velocity of ozone molecules, equalled to $3,89 * 10^{4} \mathrm{~cm} / \mathrm{sec}$, S- Teflon tubes surface area, $\mathrm{m}^{2},\left[\mathrm{O}_{3}\right]_{\mathrm{o}}$ - ozone concentration at generator outlet, equalled to $50 \mathrm{ppb}$. Both the data, which were used for calculation by formula (1), and the results of computations are presented in the table 1 below. Tube surface is equated to its geometric surface.

Table 1. Experimental results

\begin{tabular}{|c|c|c|c|c|}
\hline $\begin{array}{c}\text { Stationary signal } \\
\text { level of a sensor } \\
(\mathrm{U}, \mathrm{B})\end{array}$ & Tube length $(l, \mathrm{~cm})$ & $\begin{array}{c}\text { Geometric surface } \\
\text { of a tube }\left(\mathrm{S}, \mathrm{cm}^{2}\right)\end{array}$ & $\begin{array}{c}\text { Concentration at } \\
\text { outlet of a tube } \\
\left(\left[\mathrm{O}_{3}\right], \mathrm{ppb}\right)\end{array}$ & $\begin{array}{c}\text { Heterogeneous } \\
\text { death-rate of ozone } \\
\mathrm{O}_{3}, \gamma\end{array}$ \\
\hline 4.56 & 1 & 0,628 & 50 & - \\
\hline 4.37 & 500 & 314 & 37 & $6,58^{*} 10^{-7}$ \\
\hline 4.28 & 1000 & 628 & 27,5 & $6,55^{*} 10^{-7}$ \\
\hline
\end{tabular}

As it is obvious from the above table, the values of heterogeneous death-rate of ozone $\gamma$, which were obtained during two independent test series, carried out with the tubes of $500 \mathrm{~cm}$ and 1000 $\mathrm{cm}$, agree closely. The average value of heterogeneous death-rate of ozone $\gamma$ equals to $6,57 * 10^{-7}$ in this case.

Obtained value of heterogeneous death-rate of ozone $(\gamma)$ is one order of magnitude less than the value of $(7 \div 9)^{*} 10^{-8}$ for heterogeneous death-rate of ozone $\gamma$ on the Teflon, presented in the paper [1] with the reference to the paper [4]. The major distinction between the test conditions of our research and research, presented in the paper [4], consists in the substantial difference between flow concentrations ranges, used in the above researches. The authors of the paper [4] determined the value of the heterogeneous death-rate of ozone $(\gamma)$ under the conditions of ozone concentration of $4 \%$, which is almost 5 orders of magnitude higher than ozone concentration in our research. The problem is widely discussed in various papers of functional ozone concentration dependence of surface activity with regard of surface ozone decomposition. For wide range of substances (sea salt, ice, aluminium oxide, aluminium silicates, ammonium sulphate and hydro sulphate and others.) the results of experimental researches present the increase of the value of the heterogeneous death-rate of ozone $\gamma$ under the conditions of ozone concentration decrease in the gas phase [1]. It seems reasonable to say that the 
same effect shows up on Teflon at various ozone concentrations. Our understanding is that this fact is a good explanation of $\gamma$ values discrepancies between, obtained during our research and by the authors of the paper [4].

Discrepancies of $\gamma$ values can also result from discrepancies of surface properties of various Teflon brands, which are used during the researches, and absence of strict surface control both during our research and in the research [4]. We should also like to emphasise that in our research we have used new Teflon tubes, through which standardised ozone - air mixture was pumped. The above mixture did not contained foreign inclusions. Under the conditions of evaluation of working zone air composition, of prolonged atmosphere monitoring, and also during ozone concentrations measurements in the course of technological operations, the surface of communications will be covered by dust particles and other foreign substances which will influence the value of heterogeneous deathrate of ozone $(\gamma)$ and may result in erroneous assessment of ozone losses, for instance, by formula (1).

The most efficient mode of ozone losses control and assessment comprises direct measurements of ozone concentrations at the inlets and outlets of the installations and communication lines. Such measurements can be carried out rather easily and quickly by means of semiconductor sensor, i.e. diminutive device, which allows obtaining the results during several minutes or even several seconds. It is obvious that by means of SCS ozone losses can be easily determined not only on the Teflon communication surfaces, but also on the surfaces of other systems, produced of various materials and their combinations, in the communication lines of various length and shape and independently of their state and condition.

\section{Acknowledgement}

Elaboration is funded by ISTC, project 1931.

\section{References and Notes}

1. Lunin, V.V.; Popovich, M.P.; Tkachenko, S.N. Physical Chemistry of ozone. Moscow State University Publisher. 1998.

2. Miasnikov, I.A.; Suckarev, V.Y.; Kupriyanov, L.Yu.; Zavyalov, S.A. Semiconductor sensors in physical-chemical studies. (Handbook of sensors and actuators 4). Kupriyanov,. L.Yu, Ed.; Elsevier: Amsterdam, New York, Tokyo, 1996, 400 p.

3. Obvintseva, L.A.; Gutman, E.E.; Gubanova, D.P. Semiconductor method application for investigation of photochemical reactions with chlorine and its oxygen compounds. Optics of atmosphere and ocean. 1998, Vol. 11, 1.

4. Skoblikova, A.L. Investigation of ozone heterogeneous decomposition and its evaluation in the atmosphere. Author's abstract for Ph.D. thesis (physics\& mathematics). 1989, Leningrad.

Sample Availability: Available from the authors.

(C) 2003 by MDPI (http://www.mdpi.org). Reproduction is permitted for noncommercial purposes. 